\title{
Polar Ozone and Aerosol Measurement III measurements of water vapor in the upper troposphere and lowermost stratosphere
}

\author{
Gerald E. Nedoluha, Richard M. Bevilacqua, and Karl W. Hoppel \\ Naval Research Laboratory, Washington, D.C., USA
}

Jerry D. Lumpe

Computational Physics Inc., Fairfax, Virginia, USA

Herman Smit

Forschungszentrum Jülich, Jülich, Germany

Received 30 April 2001; revised 9 July 2001; accepted 10 July 2001; published 30 May 2002.

[1] We present water vapor measurements made by the Polar Ozone and Aerosol Measurement (POAM) III instrument since May 1998 in the upper troposphere and lowermost stratosphere. While POAM III is primarily a stratospheric instrument, many of the POAM III occultation measurements allow for the retrieval of water vapor in the upper troposphere. The Measurements of Ozone and Water Vapor by Airbus In-Service Aircraft (MOZAIC) instruments provide a large number of coincident measurements and thus offer the best opportunity to validate POAM measurements in the highly spatially variable regions of the upper troposphere-lowermost stratosphere, where the mixing ratios are much larger than those found throughout most of the stratosphere. The comparison shows that there is no statistically significant difference in the response of the two instruments to changes in water vapor and that in the regime where the MOZAIC measurements are thought to be most accurate, the water vapor mixing ratios measured by POAM are $10 \%$ higher. The POAM III Northern Hemisphere measurements are taken from $55^{\circ}$ to $71^{\circ}$ and show a qualitatively reasonable seasonal variation, with high mixing ratios in the upper troposphere in the summer and low mixing ratios in the winter. Comparisons of the seasonal variations of the POAM measurements with those from the upper tropospheric Microwave Limb Sounder (MLS) measurements from the early 1990s show qualitative similarities. The $\sim 1 \mathrm{~km}$ vertical resolution of POAM measurements allows us to study in greater detail than other satellite instruments the complex variations in water vapor that occur in the upper troposphere and lowermost stratosphere. Among the interesting features observed is a rise in the level of the highlatitude hygropause from April through September. INDEX TERMS: 0340 Atmospheric Composition and Structure: Middle atmosphere-composition and chemistry; 0341 Atmospheric Composition and Structure: Middle atmosphere — constituent transport and chemistry (3334); 0368 Atmospheric Composition and Structure: Troposphere - constituent transport and chemistry; KEYWORDS: water vapor, lowermost stratosphere, upper troposphere

\section{Introduction}

[2] Water vapor is the most important greenhouse gas in the Earth's atmosphere; hence any trends in atmospheric water vapor will have important implications for global warming. The precise effect of changes in humidity will depend on the altitude at which these changes occur [Pierrehumbert, 1994], with changes in humidity in the upper troposphere producing a disproportionately large impact on outgoing longwave radiation. It has been estimated that the radiative effect of a $12-25 \%$ change in tropospheric water vapor is comparable to a doubling of $\mathrm{CO}_{2}$ [Harries, 1996]. Furthermore, water vapor is involved in several potentially important global warming feedback mechanisms. Currently, even the net sign of these feedbacks is uncertain. Intuitively, rising surface temperature should result in an increase in water vapor because of increasing evaporation. The direct radiative effect of the increased water vapor represents a positive feedback mechanism. However, it

Copyright 2002 by the American Geophysical Union. 0148-0227/02/2001JD000793 has been suggested [Lindzen, 1990] that increasing surface temperatures will result in more vigorous convection that could, in turn, tend to dry the upper troposphere. This would act as a negative global warming feedback. Given this uncertainty, and the overall importance of atmospheric water vapor to global warming, careful monitoring of water vapor in the upper troposphere-lower stratosphere (UT-LS) is essential.

[3] Despite the importance of accurate measurements of humidity in the UT-LS region, there are as yet few instruments that provide large data sets of measurements both in the upper troposphere and in the lowermost stratosphere. The most extensive satellite data set comes from the UARS Microwave Limb Sounder (MLS), which provided measurements at 464, 316, 215, and $147 \mathrm{hPa}$ from 1991 to 1997 [Read et al., 2001]. The most extensive in situ data set for the upper troposphere is currently provided by the Measurements of Ozone and Water Vapor by Airbus In-Service Aircraft (MOZAIC) instruments. These instruments, employed aboard commercial aircraft, have been taking measurements since 1993 [Marenco et al., 1998]. Balloon-borne instruments from the Climate Monitoring and Diagnostics Laboratory (CMDL) provide 


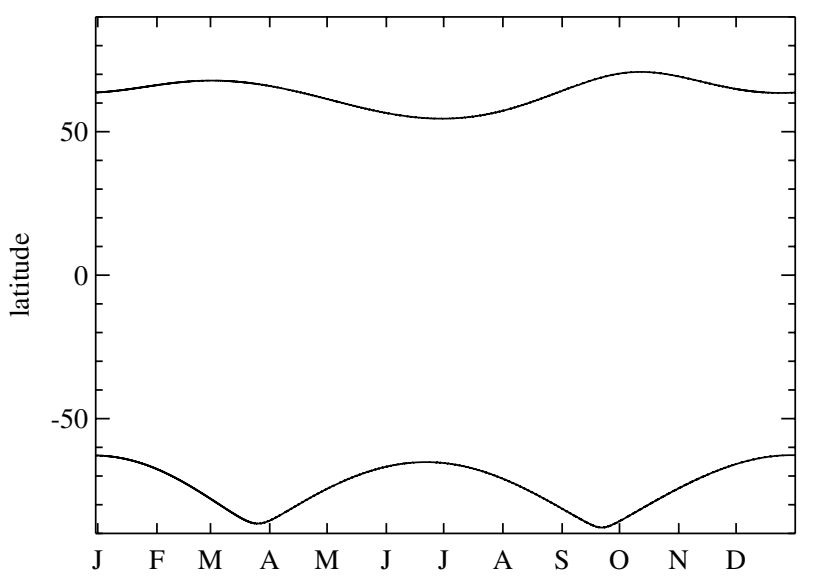

Figure 1. Latitude of the POAM III measurements as a function of season.

the longest water vapor data set covering the UT-LS region [Oltmans and Hofmann, 1995].

[4] Water vapor measurements obtained with Polar Ozone and Aerosol Measurement (POAM III) have the potential to add in a significant way to the sparse UT-LS database. The POAM instrument was designed for stratospheric measurements, but in cloudfree conditions measurements can be made into the troposphere. In this paper we present, for the first time, POAM water vapor measurements in the UT-LS region. We make detailed comparisons with coincident measurements obtained in the MOZAIC measurement program. We also show the seasonal evolution of water vapor in this region and compare this evolution to that obtained with MLS and by the CMDL group. Finally, we discuss implications of the observed seasonal variations regarding the factors important in controlling the water vapor distribution in this critically important region.

\section{POAM Measurements}

[5] The POAM III instrument, like the POAM II instrument that made measurements from 1993 to 1996, is a visible/near-infrared solar occultation photometer that measures stratospheric constituents in the high latitudes of both hemispheres. First measurements were obtained on 17 April 1998. The POAM III measurement complement includes $\mathrm{O}_{3}$, water vapor, $\mathrm{NO}_{2}$, and aerosol extinction. More detailed descriptions of the POAM III instrument and early validation results are given by Lucke et al. [1999]. Meteorological data from the UK Meteorological Office (UKMO) are used both in the POAM III retrieval and in subsequent analyses.

[6] Figure 1 shows the latitude of the POAM measurements in the Northern and Southern Hemispheres. Because of the latitudinal variation of the POAM measurements it can be difficult to separate the effects of changes in season and changes in latitude, especially in the Southern Hemisphere, where the measurements range from $62^{\circ}$ to $88^{\circ}$. In the Northern Hemisphere the latitudinal variations are much smaller and range from $55^{\circ}$ to $71^{\circ}$.

[7] All results shown here were obtained with the version 3 retrieval algorithm, which is described by J. D. Lumpe et al. (manuscript in preparation, 2001). Unlike the MLS UT-LS water vapor measurements, which use a retrieval scheme independent of that used for the MLS stratospheric water vapor measurements, the POAM measurements in this region are obtained by merely extending the operational version 3 algorithm to lower altitudes. In both the stratospheric and tropospheric retrievals the water vapor concentration is obtained from the difference between the measured slant optical depth at $936 \mathrm{~nm}$ (coincident with a water vapor absorption feature) and that at $922 \mathrm{~nm}$ (displaced from the water vapor feature). Many of the POAM retrievals therefore offer seamless profiles of water vapor mixing ratio that cover altitudes from the upper troposphere to the lower mesosphere. Two such profiles are shown in Figure 2.

[8] Since there are often very large vertical gradients in water vapor mixing ratio in the UT-LS region, vertical resolution is an important issue in UT-LS measurements. The vertical resolution of the POAM water vapor measurements in the UT-LS region is $\sim 1 \mathrm{~km}$ (J. D. Lumpe et al., manuscript in preparation, 2001). While this vertical resolution is certainly coarser than that provided by aircraft and balloon data, it is finer than that provided by the MLS measurements.

[9] POAM is a solar occultation instrument, and as described by Lucke et al. [1999], a limitation of this type of sensor is that a long, relatively cloud-free line of sight is required in order to have sufficient solar luminosity to maintain track of the Sun. When the Sun becomes sufficiently obscured, it is no longer possible to track the Sun, and the measurement scan is terminated. Tracking is maintained into the troposphere (defined here as that region with potential vorticity less than $2 \times 10^{-6} \mathrm{~K} \mathrm{~m}^{2}$ $\mathrm{kg}^{-1} \mathrm{~s}^{-1}$ (2 PVU) [Appenzeller et al., 1996]) on $\sim 63 \%$ of Northern Hemisphere measurements and $\sim 50 \%$ of Southern Hemisphere measurements.

[10] In some cases there is sufficient solar luminosity to allow the POAM instrument to track the Sun, but the retrievals may fail to converge to a solution, often because of instabilities in the aerosol separation component of the retrieval algorithm. In addition, even if the retrieval does converge, there may be a large uncertainty in water vapor mixing ratio because of large aerosol optical depths. Here, as done by Nedoluha et al. [2000], we have chosen to exclude all measurements for which the ratio of the aerosol extinction of that measurement is more than a factor of 15 larger than the average water vapor extinction at that altitude. In addition, we have eliminated any measurements either $1 \mathrm{~km}$ above or below such a region and have also excluded measurements $1 \mathrm{~km}$ above the lowest altitude at which retrievals were possible. These additional restrictions reduce the fraction of retrievals that can be extended into the troposphere to $24 \%$ in the Northern Hemisphere and $21 \%$ in the Southern Hemisphere. Future versions of the retrieval algorithm may make it possible to increase these percentages somewhat, but there will always remain a fundamental limit determined by the ability of the instrument to track the Sun.

[11] The limitation on the use of POAM measurements in regions of high aerosol extinction can cause a sampling bias

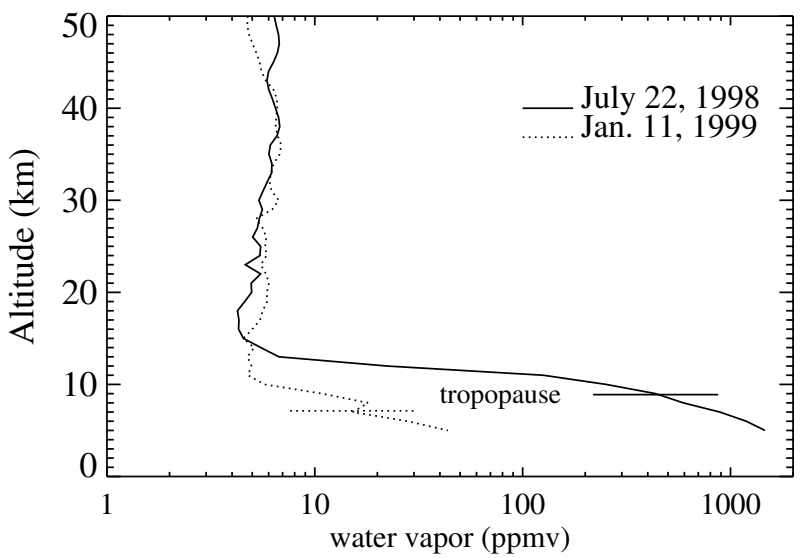

Figure 2. Water vapor profiles measured by POAM on 22 July 221998 (at $56^{\circ} \mathrm{N}$ ), and 11 January 1999 (at $64^{\circ} \mathrm{N}$ ). Also shown is the altitude of the 2 potential vorticity unit (PVU) tropopause. 
which, depending upon conditions, can lead to the preferential exclusion of regions with either high or low water vapor mixing ratios. Measurements in regions with high water vapor mixing ratios may be preferentially excluded because POAM cannot retrieve in regions where high humidity causes clouds to form. This is probably the most important source of sampling bias in the POAM measurements. Despite these limitations on the POAM tropospheric water vapor measurements, the dearth of other available measurements in the upper troposphere and the importance of this region to radiative balance calculations make this a valuable data set.

[12] In Figure 3 we show, as a function of altitude and date, the fraction of measurements for which it is possible to obtain useful retrievals. In this figure, as in all of the other contour plots shown, the results are calculated from nominal "daily averages," which are calculated from the 14 measurements per day obtained by POAM in each hemisphere. However, since it is not always possible to obtain 14 good measurements per day, this averaging period is often extended to include several days, so as to include at least 14 good measurements. Thus the data at the lowest altitudes, where it is most difficult to obtain good measurements, are generally smoothed over a period of several days.

[13] As can be seen in Figure 3, the minimum altitude reached by the retrievals clearly has a strong seasonal dependence. Also shown in Figure 3 is the maximum dynamical tropopause height for each daily average of POAM measurements included in the analysis. We have chosen to show the maximum tropopause height to emphasize that many of the high water vapor mixing ratios seen in the lowermost stratosphere are not caused by averaging together tropospheric and stratospheric measurements (given the 2 PVU definition of the tropopause). In the Northern Hemisphere the fraction of measurements possible at the tropopause is greatest in winter, despite the lower altitude of the tropopause during this season. The smaller fraction of available measurements in the Southern Hemisphere is caused by the presence of polar stratospheric clouds (PSCs), which limits observations in the lower stratosphere and below from mid-July to mid-September.

[14] In Figure 4 we show the individual water vapor mixing ratio measurements interpolated to a 2 PVU tropopause in the Northern Hemisphere. This figure helps to emphasize both the number of POAM observations in the troposphere and the variability of the water vapor mixing ratio at the tropopause. While the variability of the water vapor mixing ratio at the tropopause is much higher than in the stratosphere, there remains a clear seasonal variation, with the highest water vapor mixing ratios at the tropopause being measured in the summer. There are at least two potential causes for this seasonal variability. Increased descent of dry stratospheric air into the tropopause region in the winter should certainly decrease the average mixing ratio. In addition, seasonal variations in tropospheric temperature will tend to decrease the water vapor mixing ratio in the upper troposphere during the northern latitude winter. If we use a 3.5 PVU tropopause, as suggested by Hoerling et al. [1991], then the mixing ratios shown in Figure 4 will decrease by $\sim 50 \%$, but the seasonal variation will remain qualitatively very similar.

\section{Validation of POAM Measurements: Comparisons With MOZAIC}

[15] Throughout most of the stratosphere, where water vapor mixing ratios generally vary slowly with distance, it is possible to perform useful validation studies with a small number of coincident measurements made within a few hours and a few hundred kilometers of each other. POAM water vapor measurements in these regions of the stratosphere have been, and are being, validated in several other studies. Stratospheric Processes and
Their Role in Climate (SPARC) [2000] showed comparisons of POAM version 2 data with several other instruments. A more detailed comparison between Halogen Occultation Experiment (HALOE) and POAM version 3 data is currently underway. These studies show that the POAM stratospheric water vapor measurements are in good agreement with other instruments. The difference between POAM and HALOE in the stratosphere is generally within $10 \%$ for the POAM version 3 data.

[16] In this paper we are interested in validating the POAM measurements in regions where the mixing ratio is significantly greater than is generally found throughout most of the stratosphere, i.e., mixing ratios greater than $\sim 10$ ppmv. Regions in the UT-LS with mixing ratios of this magnitude generally have very high spatial variability. A good example of the spatial variability in the UT-LS region, and the differences observed by different in situ measurements taken as close together as possible, is given by Helten et al. [1999]. Because individual comparisons may not provide a meaningful validation of the POAM measurements in regions with large spatial variability, we need to compare the POAM measurements with a data set that provides a large number of coincidences in such regions. A sufficiently large data set will enable us to determine the presence of systematic errors in the POAM data.

[17] The MOZAIC project places instruments aboard commercial aircraft to measure several constituents as well as temperature and pressure. These instruments have been taking measurements since 1993 [Marenco et al., 1998]. Most of these measurements are taken at aircraft cruise altitudes $(9-12 \mathrm{~km})$. The MOZAIC project provides by far the largest data set of water vapor measurements coincident with the POAM measurements in the UT-LS region. Helten et al. [1999] show that for mixing ratios of 80-120 ppmv the capacitive humidity sensors used by MOZAIC agree to within $5 \%$ with the cryogenic frost point hygrometer employed by the Pollution from Aircraft Emissions in the North Atlantic Flight Corridor (POLINAT) project.

[18] The validation of measurements in a region of very large spatial variability would ideally be accomplished by comparing two observations that measure precisely the same volume of air. The POAM measurements, however, have an along-path resolution of $\sim 250 \mathrm{~km}$, an across-path resolution of $\sim 30 \mathrm{~km}$, and a vertical resolution of $\sim 1 \mathrm{~km}$, so even within this sampling volume there will be significant variability. Even the closest coincidences between the POAM and in situ MOZAIC measurements (or between any other sets of water vapor measurements in the tropopause region when at least one instrument is space-based) are therefore likely to measure volumes of air that have significantly different water vapor mixing ratios.

[19] Because the air masses being sampled are not identical, we must ensure that no sampling bias is introduced. A bias could, for example, be introduced if a MOZAIC measurement fulfilling the coincidence criteria is sampling a region where, because of high aerosol optical depths, POAM is unable to sample. While POAM clear air measurements are validated even in the very dry regions of the stratosphere (R. M. Bevilacqua et al., manuscript in preparation, 2001), measurements of relative humidity below $5 \%$ in the MOZAIC database are considered to be below the detection limit. In order to minimize any biases we have included only coincident measurements where both instruments measure relative humidity values between $5 \%$ and $100 \%$.

[20] If we use matching criteria of $250 \mathrm{~km}$ and 6 hours and limit the humidity range of the measurements used as indicated above, there remain a large number of coincidences between the MOZAIC and POAM Northern Hemisphere measurements, as is shown in Figure 5. The distance-matching criterion has been chosen to match approximately the horizontal path sampled by a POAM measurement. Given this distance constraint, we find that any further tightening of the time constraint does not significantly improve the correlation of the two data sets. 

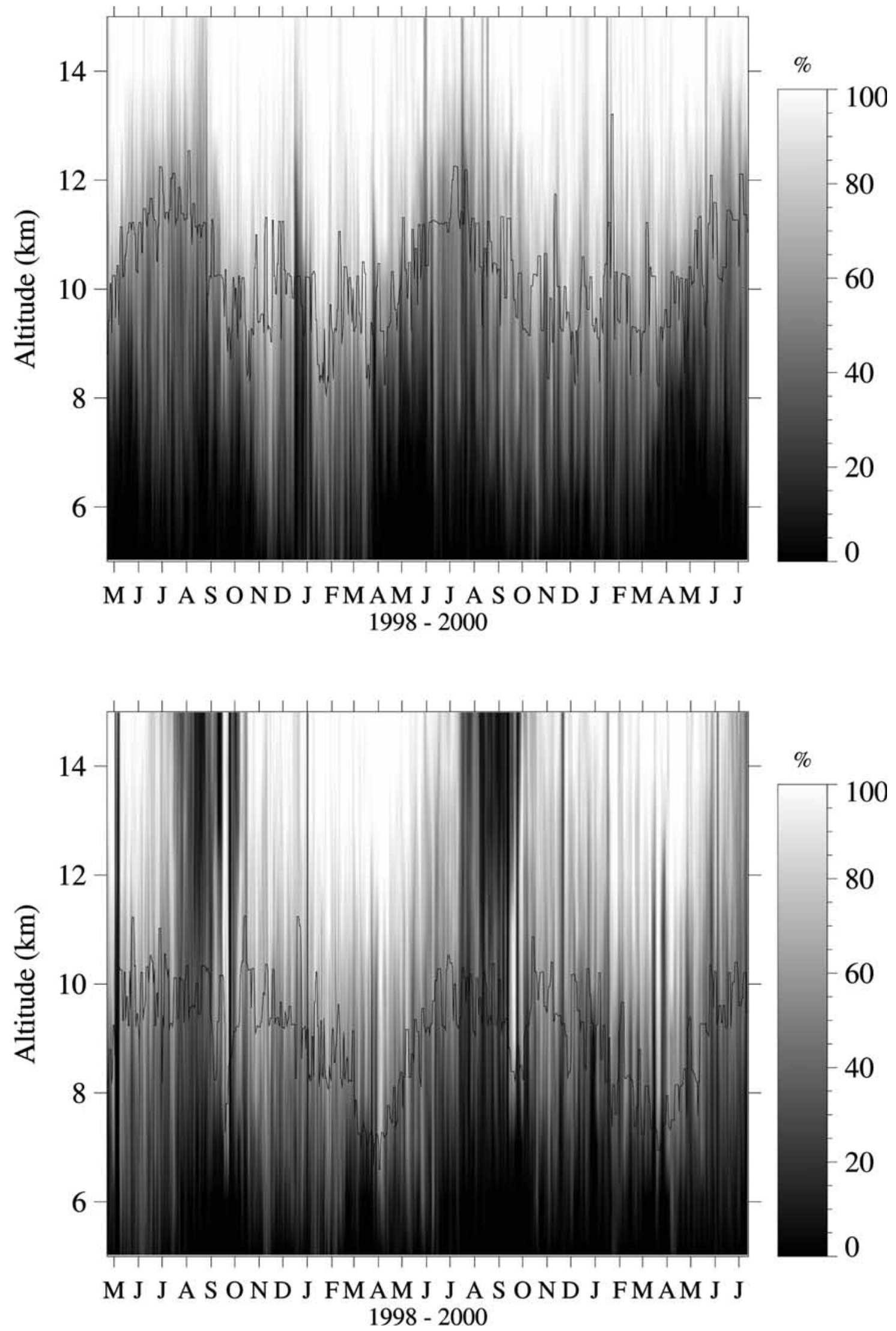

Figure 3. Fraction of good retrievals for each "daily average." In order to ensure that each daily average includes at least 14 good measurements it is sometimes necessary to average over several days. Also indicated is the maximum tropopause height for each daily average. See color version of this figure at back of this issue. 


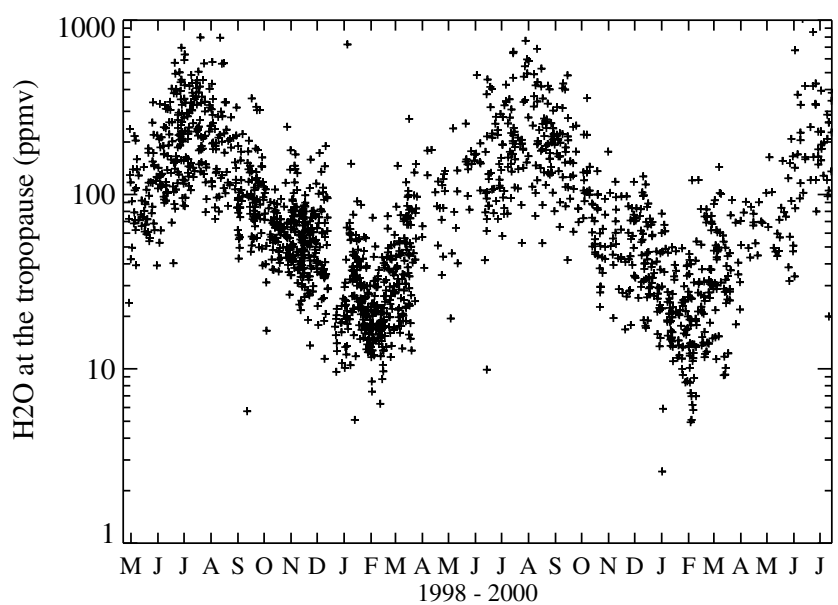

Figure 4. Water vapor mixing ratio at the tropopause for the POAM Northern Hemisphere $\left(55^{\circ}\right.$ to $\left.71^{\circ}\right)$ measurements.

[21] The MOZAIC and POAM measurements can be reasonably compared in relative humidity, mixing ratio, or concentration (the fundamental POAM measurement). Whereas the MOZAIC water vapor measurements are taken together with the local temperature, there is no POAM measurement of temperature. POAM mixing ratios and humidities must therefore be calculated using a temperature estimate from the UKMO analysis. Thus the most accurate comparison of POAM and MOZAIC data is performed in concentration. We shall show comparisons both in mixing ratio and in concentration.

[22] In Figure 6 we plot a comparison of POAM and MOZAIC measurements taken from April 1998 through February 2000. Each MOZAIC data point in Figure 6 represents an average of all of the MOZAIC measurements taken within the prescribed coincidence criteria of a POAM measurement. In order to avoid averaging together MOZAIC data from different pressure levels, we have dropped any data points not taken at a pressure within $\pm 10 \%$ of the pressure level used for the comparison. Each POAM coincident water vapor value is then calculated by interpolating to the average pressure of the coincident MOZAIC measurements. While there are clearly large point-to-point differences, the instruments show similar water vapor concentrations during each season.

[23] Since Helten et al. [1999] validated measurements in the $80-120$ ppmv range, and since capacitive humidity sensors generally work better as the water vapor mixing ratio is increased above this range, the MOZAIC measurements with mixing ratios $>80$ ppmv should be accurate. The average POAM water vapor mixing ratio from the 42 coincidences where both instruments measure $>80 \mathrm{ppmv}$ is $10 \%$ higher than that of MOZAIC. The standard deviation of the fractional difference with this bias removed $\left(\sigma_{\text {dif }}\right)$ is $33 \%$. Since $\sigma_{\text {dif }} / n^{1 / 2}=5 \%$, the $10 \%$ bias calculated using this comparison method is statistically significant at the $2 \sigma$ level.

[24] MOZAIC measurements for smaller water vapor mixing ratios, while not validated, may nevertheless provide a useful comparison of the sensitivity of the POAM and MOZAIC instruments to changes in water vapor. In Figure 7 we show the linear fit for the coincident POAM and MOZAIC measurements calculated using the FITEXY routine from Press et al. [1992], which takes into account the uncertainties in both sets of measurements. This should allow us to determine whether there is any systematic bias in the sensitivity of either set of measurements to changes in water vapor. However, since the relative estimate of the random error in the two sets of measurements will directly affect the slope of the linear fit, we need to first estimate the relative random uncertainty in the two sets of measurements [cf. Nedoluha et al., 1997].

[25] The correlation coefficient for these two data sets is 0.78 . We can use this value to estimate the random uncertainty in the data. If we use one of the two sets of measurements to represent the true water vapor concentration, and apply a random variation with a standard deviation of $50 \%$ to both measurements, then the resultant data set has a correlation coefficient of $\sim 0.78$. This could indicate that both sets of measurements have a random error of $50 \%$ or that one instrument has a random error of $>50 \%$. A random error of $50 \%$ is, however, far larger than the estimated random errors of either the MOZAIC or POAM instruments. This suggests that the difference between the measurements is instead dominated by geophysical differences. Given the coincidence criteria we have chosen, such large geophysical differences would be implausible for an upper stratospheric data set, but they are plausible in the UT-LS region, where these intercomparisons are being made. We
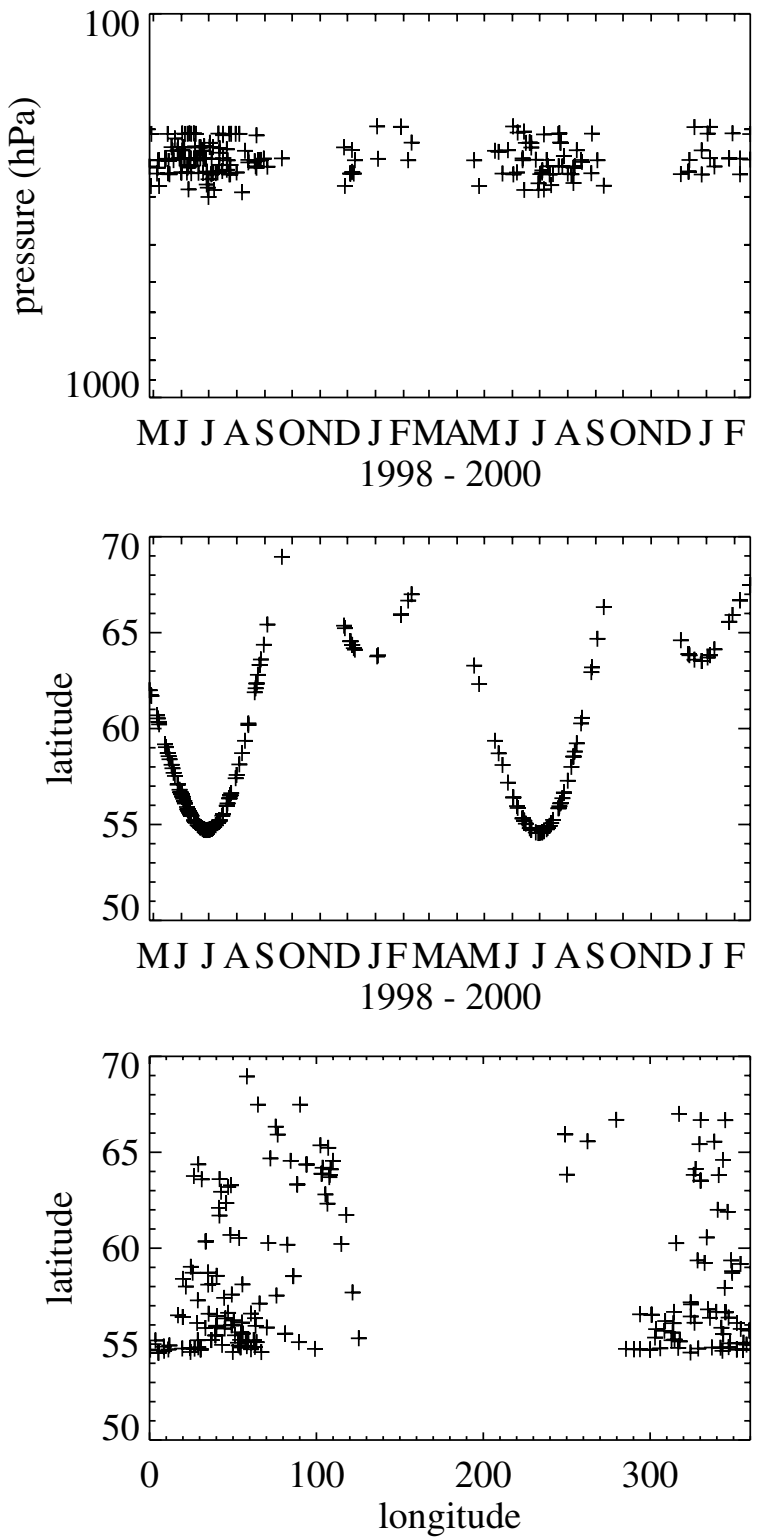

Figure 5. Positions of POAM and MOZAIC measurements that are coincident within $250 \mathrm{~km}$ and 6 hours and meet the other restrictions described in the text. 


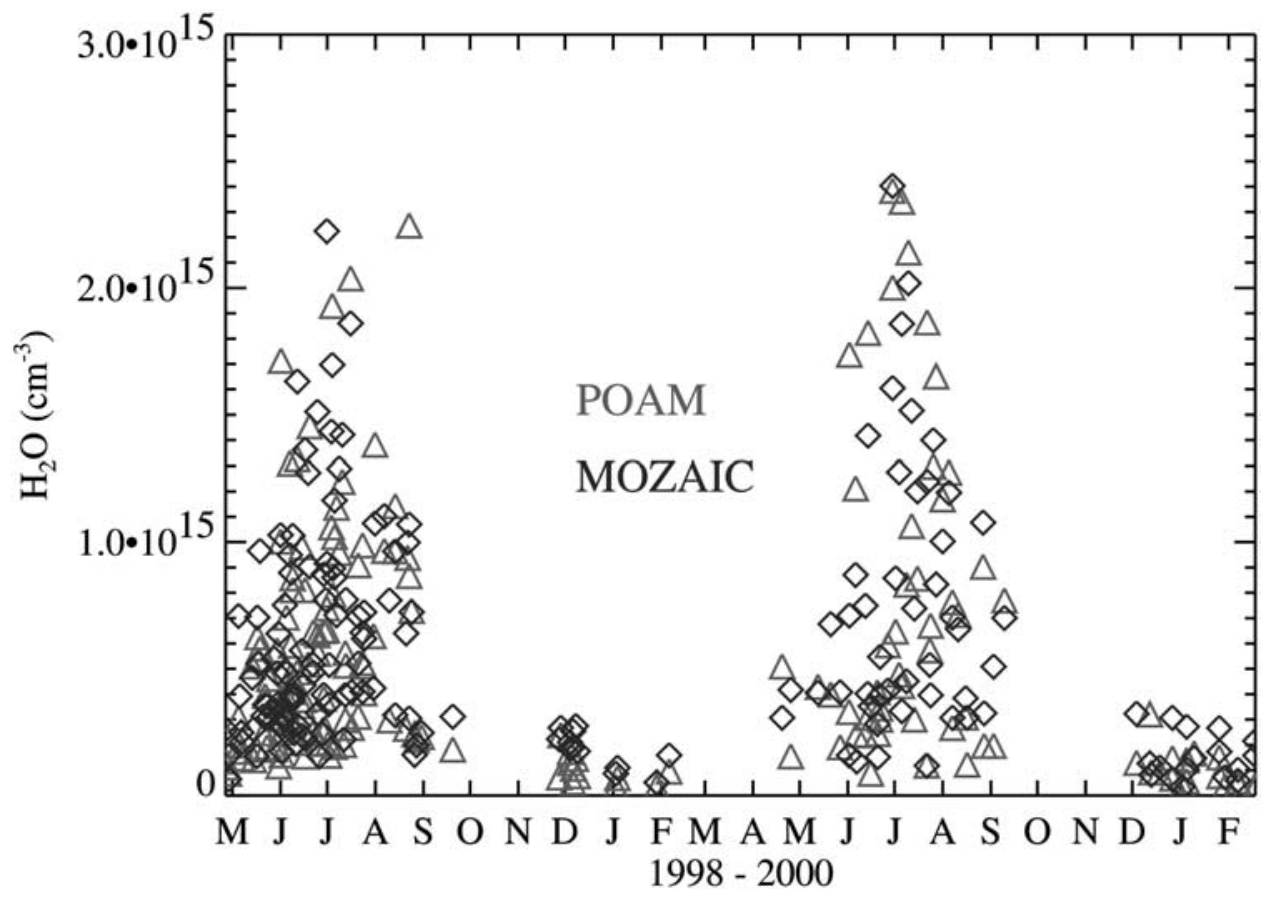

Figure 6. Water vapor concentrations from the coincident POAM (triangles) and MOZAIC (diamonds) measurements indicated in Figure 5. See color version of this figure at back of this issue.

have therefore set the estimated uncertainties for both instruments equal to $50 \%$ in calculating the linear fit shown in Figure 7. This gives a best fit slope of $1.02 \pm 0.09$, with a $y$ offset of $2.37 \times 10^{13}$ $\pm 1.19 \times 10^{13} \mathrm{~cm}^{-3}$. Thus the slope is not significantly different from 1 , indicating that there is no significant systematic bias in the sensitivity of the two instruments to changes in water vapor. The nonzero $y$ offset may indicate that for very small mixing ratios the estimated random error of $\sim 50 \%$ is too small. However, adding a constant random error term to both measurements does not eliminate the nonzero $y$ offset between the two sets of measurements. While a constant offset of $\sim 1-2 \times 10^{13} \mathrm{~cm}^{-3}$ would significantly affect the POAM stratospheric measurements, it certainly seems plausible that the MOZAIC instruments, which are not optimized for measurements of such small concentrations, might have a small constant offset of this magnitude. Alternatively, a random error $\sim 1 \times 10^{14} \mathrm{~cm}^{-3}$ in the MOZAIC measurements would also remove the statistical significance of the difference in the two sets of measurements.

[26] We have argued that this comparison is best done in concentration, but as a check we also performed the calculation in mixing ratio and found very similar results. The maximum coincident mixing ratio is $\sim 260$ ppmv, and the correlation coefficient is 0.70 . The best fit slope when the measurements are compared in mixing ratio is $0.99 \pm 0.08$, with a $y$ offset of $3.6 \pm 1.6 \mathrm{ppmv}$.

[27] The comparisons with MOZAIC therefore show both that in regions where the mixing ratio is $>80 \mathrm{ppmv}$ the POAM measurements are $\sim 10 \%$ higher than MOZAIC and that over a large range of mixing ratios the POAM and MOZAIC instruments show no statistically significant difference in their sensitivity to changes in mixing ratio. These comparisons, combined with the HALOE-POAM comparisons given by R. M. Bevilacqua et al. (manuscript in preparation, 2001), show that POAM measurements agree to within $\sim 10 \%$ for mixing ratios ranging from stratospheric values of a few ppmv, all the way up to tropospheric values of several hundred ppmv. As for the random error in the POAM data in the presence of high water vapor concentrations, what we conclude from the results presented here is that this error term is smaller than the geophysical variability inherent in a comparison between an in situ measurement and a solar occultation measurement at $1 \mathrm{~km}$ vertical resolution.

\section{Seasonal Variations}

[28] In Figure 8 we show the "daily average" water vapor mixing ratio in the troposphere and lower stratosphere for the

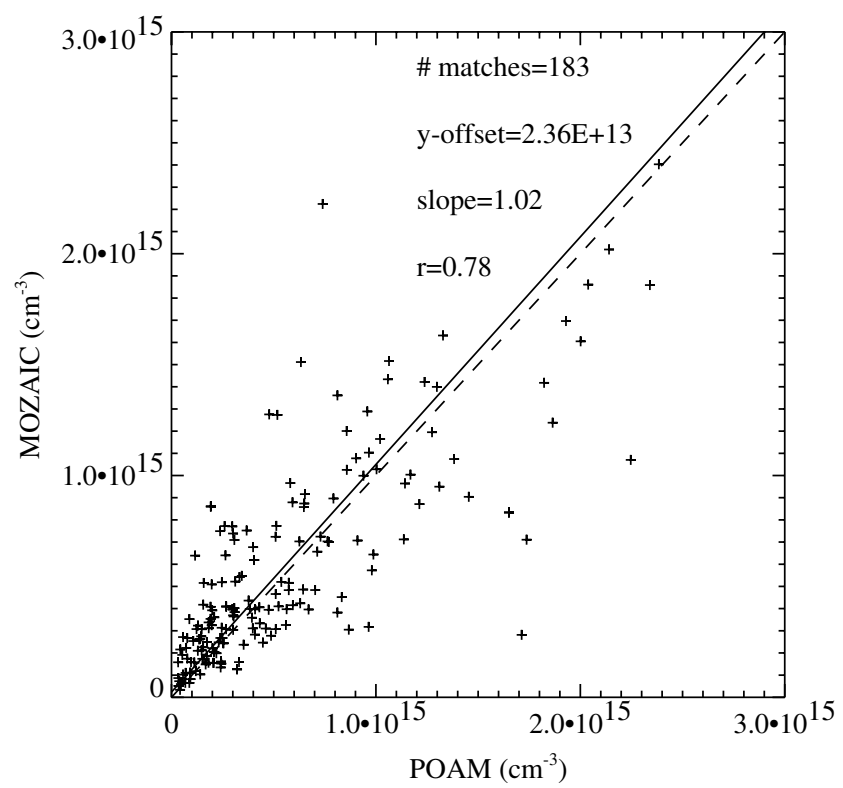

Figure 7. Water vapor concentrations and the linear best fit for the coincident POAM and MOZAIC measurements indicated in Figure 5 . 

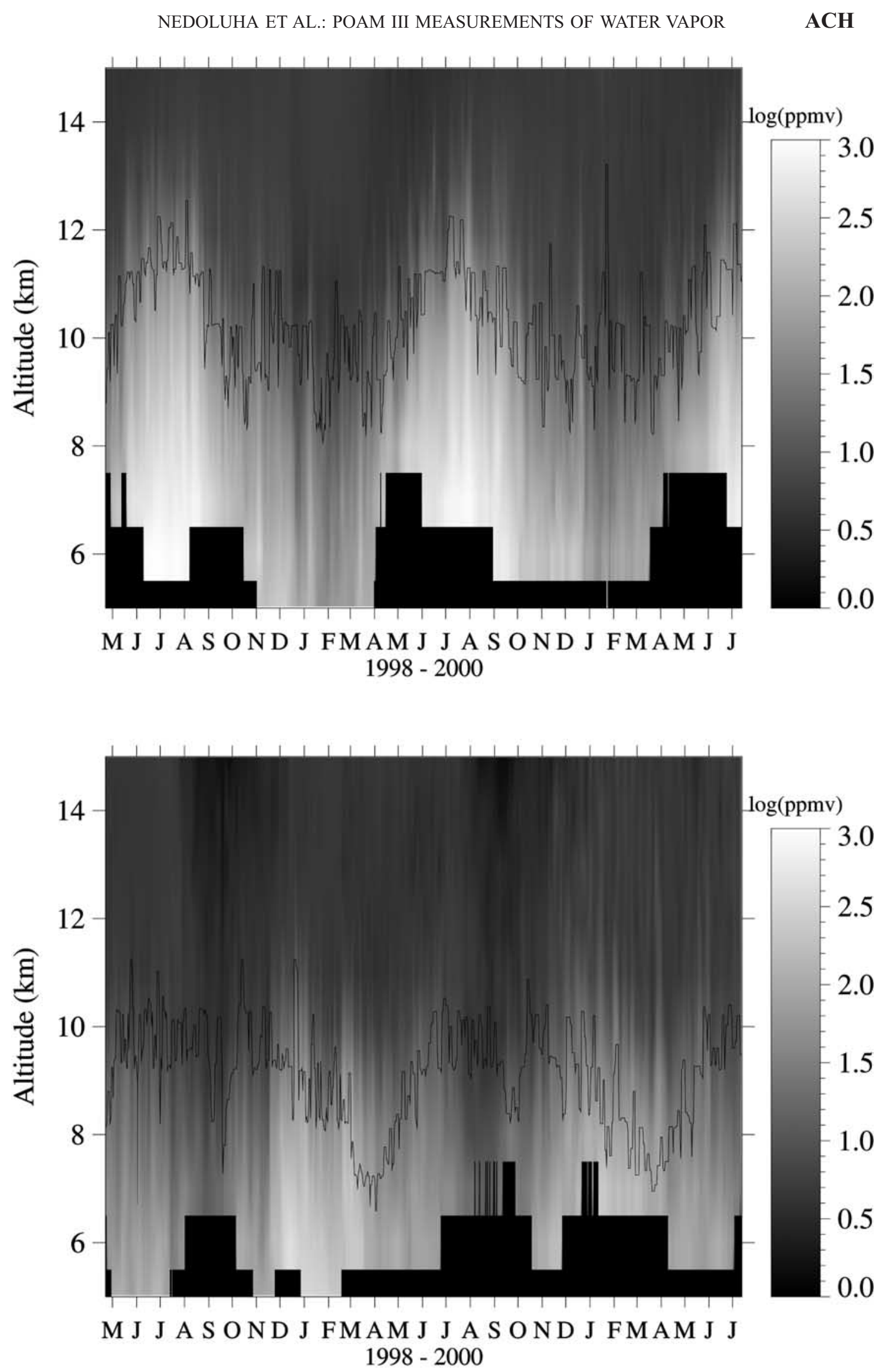

Figure 8. Water vapor mixing ratio measured by POAM at $55^{\circ} \mathrm{N}$ to $71^{\circ} \mathrm{N}$ in the troposphere and lowermost stratosphere. Note the logarithmic scale. The data are averaged as in Figure 3. Altitudes where $<14$ measurements are available over a 29 day period have been blacked out. Also indicated is the maximum 2 PVU tropopause height for the averaging period. See color version of this figure at back of this issue. 
Table 1. Average Mixing Ratios for MLS and POAM for Two Pressure Surfaces in January and July

\begin{tabular}{|c|c|c|c|c|c|c|}
\hline \multirow[t]{2}{*}{ Pressure, $\mathrm{hPa}$} & \multicolumn{3}{|c|}{ January (Latitude $65^{\circ} \mathrm{N}$ ) } & \multicolumn{3}{|c|}{ July (Latitude $56^{\circ} \mathrm{N}$ ) } \\
\hline & $\begin{array}{l}\text { MLS, } \\
\text { ppmv }\end{array}$ & $\begin{array}{c}\text { POAM, } \\
\text { ppmv }\end{array}$ & $\begin{array}{c}\text { Number of POAM } \\
\text { Retrievals }\end{array}$ & $\begin{array}{l}\text { MLS, } \\
\text { ppmv }\end{array}$ & $\begin{array}{l}\text { POAM, } \\
\text { ppmv }\end{array}$ & $\begin{array}{c}\text { Number of POAM } \\
\text { Retrievals }\end{array}$ \\
\hline 215 & 5.2 & 5.8 & 564 & 27.2 & 42.0 & 313 \\
\hline 316 & 37.3 & 21.8 & 311 & 271.4 & 275.6 & 166 \\
\hline
\end{tabular}

${ }^{a}$ Also shown is the total number of useful POAM retrievals available for each comparison.

entire POAM data set. The blacked-out regions in Figure 8 indicate those periods during which 14 good measurements were not possible over a 29 day period. As in Figure 3, we also indicate the tropopause height. In the Northern Hemisphere there is a clear seasonal variation with high mixing ratios and a high tropopause in the summer. In the Southern Hemisphere this correlation is not clearly evident, in part because of the larger latitudinal variations that accompany the seasonal variations for the POAM measurements in this hemisphere (Figure 1). We shall henceforth focus on the Northern Hemisphere measurements, both because of the smaller latitudinal variations in the POAM measurements in this hemisphere, and because this is where we have been able to validate the UT-LS POAM data against the MOZAIC measurements.

[29] The most extensive UT-LS water vapor satellite data set comes from the UARS Microwave Limb Sounder (MLS), which provided measurements at 464, 316, 215, and $147 \mathrm{hPa}$ from 1991 to 1997 [Read et al., 2001]. The technique used for these water vapor measurements is best suited for measuring the high levels of water vapor generally found in the troposphere and is less sensitive for mixing ratios less than $\sim 10$ ppmv. The MLS measurements provided nearly global coverage and, because they are made in the microwave, provide useful measurements even in the presence of cirrus clouds. We note that since we are comparing climatologies, and MLS measurements taken in regions with relative humidities $>100 \%$ are included in the data (these regions are set to $100 \%$ humidity [Stone et al., 2000]), POAM sampling biases may affect these comparisons.

[30] Direct comparisons with the upper tropospheric MLS measurements are unfortunately not possible because only very intermittent MLS measurements were made during the POAM III time period. A quantitative comparison is also complicated by the relatively poor vertical resolution $(\sim 3 \mathrm{~km})$ [Sandor et al., 2000] of the MLS instrument and by the inability of the POAM instrument to measure in the presence of high aerosol optical depth. Nevertheless, it is possible to qualitatively compare the observed seasonal cycles. The MLS instrument shows a peak in relative humidity at $60^{\circ} \mathrm{N}$ at 215 and $316 \mathrm{hPa}$ in July-August [Sandor et al., 1998] and also a peak in mixing ratio at $215 \mathrm{hPa}$ for this latitude in the summer [Stone et al., 2000], in agreement with the POAM measurements. In Table 1 we compare the monthly average POAM measurements with MLS zonal averages (taken from Stone et al. [2000, Plate 4]) at the average POAM latitudes in January and July. While there are differences in the zonal averages, the two data sets appear to be qualitatively in agreement.

[31] Figure 9 shows the seasonal variation of water vapor in the Northern Hemisphere UT-LS with respect to potential temperature. The linear scale of the water vapor mixing ratio shown here illustrates clearly the large variations in water vapor observed in the lowermost stratosphere. Despite the latitudinal variations in the POAM measurements, and their overall northward offset, the seasonal variation in the lowermost stratosphere remains qualitatively similar to the variations observed using balloon-borne frost point hygrometers from Boulder, Colorado $\left(\sim 40^{\circ} \mathrm{N}\right)$, by Oltmans and Hofmann [1995]. Both sets of measurements show a maximum in summer and a minimum in winter in the lowermost stratosphere. Pan et al. [1997, 2000] show a similar variation at $350 \mathrm{~K}$ from the Stratospheric Aerosol and Gas Experiment (SAGE) data, and
Rosenlof et al. [1997] show this seasonal variation at $390 \mathrm{~K}$ using the HALOE data.

[32] In addition to the seasonal variations apparent in Figure 9, we also note that there is a striking interannual variation in the summertime mixing ratios at $\sim 400-450 \mathrm{~K}$, with the 1999 values clearly lower than those observed in the summer of 1998 or 2000. This interannual variation is similar to that observed by HALOE, which generally shows a quasi-biennial oscillation (QBO) variation with higher mixing ratios in this range in even numbered years [Randel et al., 1998].

[33] The POAM measurements shown in Figure 9 are consistent with the generally accepted water vapor climatology in the UT-LS region. There are two processes which change the water vapor mixing ratio of parcels which enter in the stratosphere: freezedrying at the cold tropical tropopause and gradual methane oxidation in the stratosphere. From a study of water vapor measurements based on a number of instruments, it was found that the average entry level mixing ratio of water vapor in the stratosphere is $\sim 3-4$ ppmv [SPARC, 2000]. The mixing ratio of water vapor entering the stratosphere has a seasonal dependence (the "tropical tape recorder") [Mote et al., 1996]. Once in the stratosphere, methane oxidation will gradually cause the water vapor mixing ratio to increase, so the peak water vapor mixing ratio will generally be $\sim 6.5-7.5 \mathrm{ppmv}$. It is unlikely that any air with mixing ratios higher than this has passed through the tropical tropopause.

[34] Near $\sim 500 \mathrm{~K}$ the water vapor mixing ratios vary from $\sim 4.5$ to 6.5 ppmv throughout the year, consistent with the presence of air that has passed through the tropical tropopause and has subsequently experienced some methane oxidation. The seasonal variation is primarily caused by the wintertime descent of air with higher mixing ratios. Below this surface the variations become considerably more complex.

[35] From April through September there is a clear hygropause at $\sim 400-440 \mathrm{~K}$. Since during the summer air from the tropics is

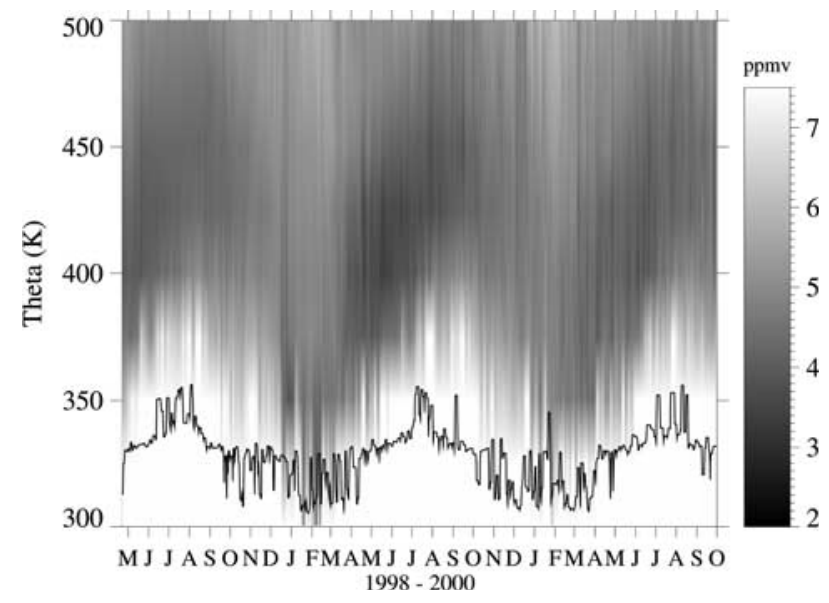

Figure 9. POAM Northern Hemisphere $\left(55^{\circ}-71^{\circ}\right)$ water vapor measurements as a function of potential temperature. The data are averaged as in Figure 8. See color version of this figure at back of this issue. 
transported to high latitudes in the lowermost stratosphere [Rosenlof et al., 1997], the vertical profile of water vapor observed by POAM is probably closely related to that of the tropics. The rise in the $\Theta$ surface of the hygropause observed by POAM is therefore probably also related to changes in the $\Theta$ surface of the hygropause at the tropics and indicates that isentropic transport from the lower tropical stratosphere must occur up to at least $440 \mathrm{~K}$. The tropical tropopause is generally found to be at $\sim 380 \mathrm{~K}$, and the variation in the potential temperature of the tropical tropopause is quite small $\sim 10 \mathrm{~K}$ [Reid and Gage, 1981]. Despite the small variation in the $\Theta$ surface of the tropical tropopause the height of the hygropause at the tropics does show a significant seasonal variation. The variations in mixing ratio observed by POAM at $\sim 400-450 \mathrm{~K}$ from April through September are quite likely to be influenced by the variations in tropical tropopause temperature, which, in turn, change the amount of water vapor entering the stratosphere.

[36] While the tropical tape recorder mechanism probably does play a role in the changing hygropause measured by POAM, we note that there are other effects that may also be important. There is likely to be some seasonal variation in the total diabatic ascent and/or descent experienced by these parcels as they are transported poleward from the tropics to the latitudes where they are observed by POAM. In addition, some of the variation in the hygropause level may be caused by the variations in the POAM measurements latitudes (see Figure 1), but the mixing ratio changes appear to be more closely tied to the seasonal cycle than to the variations in latitude.

[37] During winter, transport from the tropics to high latitudes at $\sim 350-400 \mathrm{~K}$ is much weaker than during the summer [Haynes and Shuckburgh, 2000], and high latitude air descends from above $\sim 400 \mathrm{~K}$ into the lowermost stratosphere. This descending air will have mixing ratios of $\sim 5-6$ ppmv. The water vapor mixing ratios measured by POAM from approximately November to February show that during this period the water vapor mixing ratio down to $\sim 350 \mathrm{~K}$ is consistent with the presence of stratospheric air that has experienced some methane oxidation, but in the absence of other data we cannot conclusively determine the origin of this air. Figure 9 suggests that even mixing ratios observed in the upper troposphere in January and February are sometimes consistent with the presence of stratospheric air that has descended into the upper troposphere, but we note that the tropopause height indicated on this plot is the daily maximum height. Figure 4 shows that there are a total of seven measurements with mixing ratios $<6 \mathrm{ppmv}$ at the tropopause. Determining whether or not POAM is really observing the descent of stratospheric air into the troposphere will require a more detailed analysis of these measurements combined with the POAM ozone measurements.

[38] The very high mixing ratios (i.e., $>7.5 \mathrm{ppmv}$ ) observed above the tropopause throughout much of the year, but especially during the summer months, indicate that at least a portion of this air has been transported isentropically from the tropical upper troposphere into the lowermost stratosphere without being freeze-dried down to the saturation mixing ratio of the tropical tropopause [Holton et al., 1995; Dessler et al., 1995]. The connection of these high mixing ratios to their tropical tropospheric origins is well documented with data from MLS and HALOE by Randel et al. [2001]. During summer the water vapor mixing ratio of highlatitude air observed by POAM at $\sim 350-400 \mathrm{~K}$ therefore depends largely on whether or not the measured air has passed through the tropical tropopause.

[39] The highest $\Theta$ surface on which POAM observes air that has not passed through the tropical tropopause appears to be at $\sim 370-380 \mathrm{~K}$. Although some of the variation at this $\Theta$ surface may be the result of changes in water vapor resulting from the tropical tape recorder, the POAM measurements at $\sim 370-380 \mathrm{~K}$ show a seasonal variability of the water vapor mixing ratio that is larger than that observed by HALOE at the tropical tropopause. The range of water vapor mixing ratios just above the tropical tropopause in the analysis of Randel et al. [2001] is $\sim 2.6-4.4$ ppmv, while POAM measures mixing ratios from $\sim 3.5$ to $7 \mathrm{ppmv}$ at $\sim 370-380 \mathrm{~K}$. Thus the air observed by POAM on this $\Theta$ surface seems to originate from three difference sources, depending upon season. During the winter months these levels contain a significant amount of air that has descended from the upper stratosphere, with mixing ratios of $\sim 5-6$ ppmv. During the spring these levels contain primarily air that has recently been dehydrated by passing through the tropical tropopause. Finally, during the summer and early fall, these levels contain a significant portion of this air has not passed through the tropical tropopause.

[40] As is apparent in Figure 8, the seasonal variation of the water vapor mixing ratio in the upper troposphere is roughly in phase with that in the lower stratosphere. It is not clear why these variations should be in phase, since, while much of the air in the lowermost stratosphere has probably been transported vertically in the tropics and then adiabatically from the tropical troposphere into the stratosphere, local vertical transport is likely to play a much larger role in determining water vapor mixing ratios in the upper troposphere. Given the differences in the dominant transport processes in these two regions, it seems somewhat surprising that there is no clear distinction in the variation of water vapor just above and just below the tropopause. As is apparent from the range of proposed definitions of the tropopause, however (e.g., a $2 \mathrm{~K}$ $\mathrm{km}^{-1}$ lapse rate, or a potential vorticity value of 3.5 PVU [Hoerling et al., 1991]), there is no precisely definable surface that allows one to clearly separate the stratosphere from the troposphere.

\section{Summary and Discussion}

[41] We have compared the POAM measurements with MOZAIC measurements and have shown that there is no statistically significant difference in the response of the POAM and MOZAIC instruments to changes in water vapor. We have also compared the two sets of measurements in the regime where the MOZAIC measurements are likely to be most accurate and have found that in this regime the POAM measurements are $\sim 10 \%$ higher. This validation, combined with other validation studies of POAM water vapor measurements in the stratosphere, suggests that POAM can provide a useful measure of water vapor from the upper troposphere to the lower mesosphere.

[42] The seasonal cycle in water vapor observed by POAM in the troposphere is in qualitative agreement with the MLS tropospheric water vapor measurements. The $1 \mathrm{~km}$ vertical resolution of the POAM measurements also allows us to investigate the water vapor mixing ratio at the tropopause. We find that the amount of water vapor at the tropopause in these measurements is largest in summer. This seasonal variation is generally larger than the measurement-to-measurement variation within a season.

[43] Having shown that the POAM retrievals are providing accurate water vapor measurements in the upper troposphere and in the lowermost stratosphere, we hope to be able, in future, to use these measurements to study in detail how these regions interact. The data included here show no clear division between variations in water vapor in the upper troposphere and those in the lowermost stratosphere, yet these regions are generally considered to be somewhat distinct. Future work will address the variations in water vapor mixing ratios just above and below the tropopause.

[44] Acknowledgments. We thank the UK Meteorological Office for providing the meteorological data used in this paper. We also thank Beth Stone for providing MLS data in digitized form. The POAM III instrument was sponsored by the Office of Naval Research. The French Centre National d'Etudes Spatiales operates the SPOT 4 spacecraft and has generously waived the uplink fees. Launch and initial operation of POAM were sponsored by the Air Force Space Test Program; continuing operations are performed by the Air Force Space and Missile Command. 
Support for scientific analysis of the data comes from the Naval Research Laboratory and from the NASA Atmospheric Chemistry Modeling and Analysis Program.

\section{References}

Appenzeller, C., H. C. Davies, and W. A. Norton, Fragmentation of stratospheric intrusions, J. Geophys. Res., 101, 1435-1456, 1996.

Dessler, A. E., E. J. Hintsa, E. M. Weinstock, J. G. Anderson, and K. R. Chan, Mechanisms controlling water vapor in the lower stratosphere: "A tale of two stratospheres", J. Geophys. Res., 100, 23,167-23,172, 1995.

Harries, J. E., Atmospheric radiation and atmospheric humidity, Q. J. R Meteorol. Soc., 123, 2173-2186, 1996

Haynes, P., and E. Shuckburgh, Effective diffusivity as a diagnostic of atmospheric transport, 2, Troposphere and lower stratosphere, J. Geophys. Res., 105, 22,795-22,810, 2000

Helten, M., H. G. J. Smit, D. Kley, J. Ovarlez, H. Schlager, R. Baumann, U. Schumann, P. Nedelec, and A. Marenco, In-flight comparison of MOZAIC and POLINAT water vapor measurements, J. Geophys. Res., 104, 26,087-26,096, 1999

Hoerling, M. P., T. D. Schaak, and A. J. Lenzen, Global objective tropopause analysis, Mon. Weather Rev., 119, 1816-1831, 1991.

Holton, J. R., P. H. Haynes, M. E. McIntyre, A. R. Douglass, R. B. Rood and L. Pfister, Stratosphere-troposphere exchange, Rev. Geophys., 33 403-439, 1995

Lindzen, R. S., Some coolness concerning global warming, Bull. Am Meteorol. Soc., 71, 288-299, 1990.

Lucke, R. L., et al., The Polar Ozone and Aerosol Measurement (POAM) III instrument and early validation results, J. Geophys. Res., 104 $18,785-18,800,1999$

Marenco, A., et al., Measurement of ozone and water vapor by Airbus in-service aircraft: The MOZAIC airborne program, an overview, J. Geophys. Res., 103, 25,631-25,642, 1998.

Mote, P. W., K. H. Rosenlof, M. E. McIntyre, E. S. Carr, J. C. Gille, J. R. Holton, J. S. Kinnersley, H. C. Pumphrey, J. M. Russell III, and J. W. Waters, An atmospheric tape recorder: The imprint of tropical tropopause temperature on stratospheric water vapor, J. Geophys. Res., 101, 3989-4006, 1996.

Nedoluha, G. E., R. M. Bevilacqua, R. M. Gomez, W. B. Waltman, B. C. Hicks, D. L. Thacker, J. M. Russell III, M. Abrams, H. C. Pumphrey, and B. J. Connor, A comparative study of mesospheric water vapor measurements from the ground-based water vapor millimeter-wave spectrometer and space-based instruments, J. Geophys. Res., 102, 16,647-16,661, 1997.

Nedoluha, G. E., R. M. Bevilacqua, K. W. Hoppel, M. Daehler, E. P. Shettle, J. H. Hornstein, M. D. Fromm, J. D. Lumpe, and J. E. Rosenfield POAM III measurements of dehydration in the Antarctic lower stratosphere, Geophys. Res. Lett., 27, 1683-1686, 2000.

Oltmans, S. J., and D. J. Hofmann, Increase in lower-stratospheric water vapour at a mid-latitude Northern Hemisphere site from 1981 to 1994 Nature, 374, 146-149, 1995
Pan, L. S., S. Solomon, W. Randel, J.-F. Lamarque, P. Hess, J. Gille, E.-W. Chiou, and M. P. McCormick, Hemispheric asymmetries and seasonal variations of the lowermost stratospheric water vapor and ozone derived from SAGE II data, J. Geophys. Res., 102, 28,177-28,184, 1997.

Pan, L. L., E. J. Hintsa, E. M. Stone, E. M. Weinstock, and W. J. Randel, Water vapor in the lowermost stratosphere, J. Geophys. Res., 105, 26,519-26,530, 2000

Pierrehumbert, R. T., Thermostats, radiator fins, and local runaway greenhouse, J. Atmos. Sci., 52, 1784-1806, 1994.

Press, W. H., et al., Numerical Recipes: The Art of Scientific Computing, 2nd ed., Cambridge Univ. Press,, New York, 1992.

Randel, W. J., F. Wu, J. Russell, A. E. Roche, and J. Waters, Seasonal cycles and $\mathrm{QBO}$ variations in stratospheric $\mathrm{CH}_{4}$ and $\mathrm{H}_{2} \mathrm{O}$ observed in UARS HALOE data, J. Atmos. Sci., 55, 163-185, 1998.

Randel, W. J., F. Wu, A. Gettelman, J. M. Russell III, J. M. Zawodny, and S. J. Oltmans, Seasonal variation of water vapor in the lower stratosphere observed in Halogen Occultation Experiment data, J. Geophys. Res., 106, $14,313-14,325,2001$

Read, W. G., et al., UARS Microwave Limb Sounder upper tropospheric humidity measurement: Method and validation, in press, 2001.

Reid, G. C., and K. S. Gage, On the annual variation of height of the tropical tropopause, J. Atmos. Sci., 38, 1928-1938, 1981.

Rosenlof, K. H., A. F. Tuck, K. K. Kelly, J. M. Russell III, and M. P. McCormick, Hemispheric asymmetries in water vapor and inferences about transport in the lower stratosphere, J. Geophys. Res., 102, $13,213-13,234,1997$

Sandor, B. J., et al., Seasonal behavior of tropical to midlatitude upper tropospheric water vapor from UARS MLS, J. Geophys. Res., 103, 25,935-25,947, 1998

Sandor, B. J., E. J. Jensen, E. M. Stone, W. G. Read, J. W. Waters, and J. L. Mergenthaler, Upper tropospheric humidity and thin cirrus, Geophys. Res. Lett., 27, 2645-2648, 2000

Stone, E. M., L. Pan, B. J. Sandor, W. G. Read, and J. W. Waters, Spatial distributions of upper tropospheric water vapor measurements from the UARS Microwave Limb Sounder, J. Geophys. Res., 105, 12,149$12,161,2000$

Stratospheric Processes and Their Role in Climate (SPARC), Assessment of upper tropospheric and stratospheric water vapour, SPARC Rep. 2, Verriès-le-Buisson, France, 2000

R. M. Bevilacqua, K. W. Hoppel, and G. E. Nedoluha, Naval Research Laboratory, Code 7227, 4555 Overlook Avenue,Washington DC 20375 5000, USA. (bevilacqua@nrl.navy.mil; karl.hoppel@nrl.navy.mil; nedoluha (a)nrl.navy.mil)

J. D. Lumpe, Computational Physics Inc., 2750 Prosperity Avenue, Suite 600, Fairfax, VA 22031, USA. (lumpe@cpi.com)

H. Smit, Institute for Chemistry of the Polluted Atmosphere (ICG-2), Forschungszentrum Jülich, P. O. Box 1913, D-52425 Jülich, Germany. (h.smit@kfa-juelich.de) 


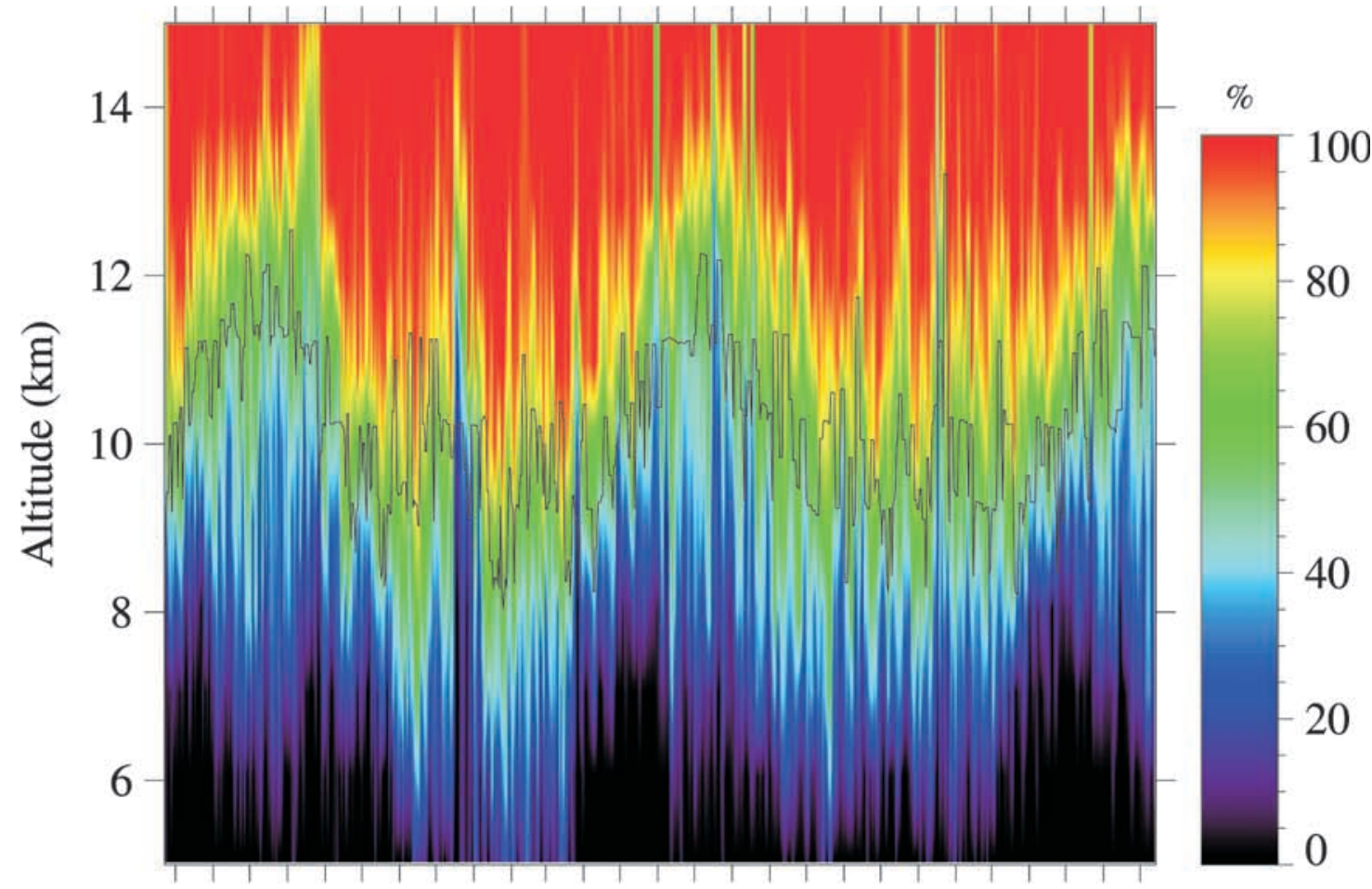

M J J A S OND J FMAM J J A S OND J FMAM J J

$1998-2000$

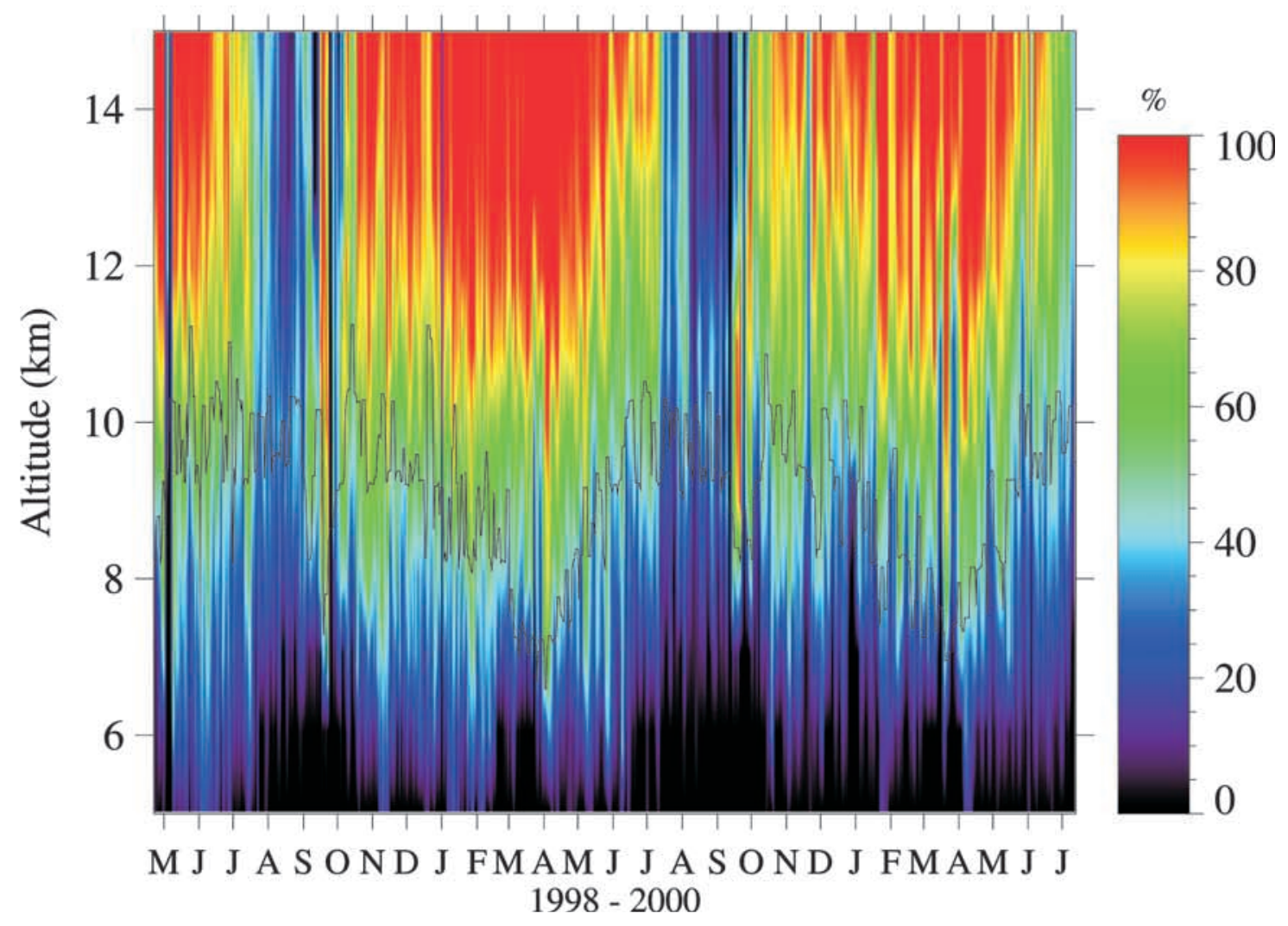

Figure 3. Fraction of good retrievals for each "daily average." In order to ensure that each daily average includes at least 14 good measurements it is sometimes necessary to average over several days. Also indicated is the maximum tropopause height for each daily average. 


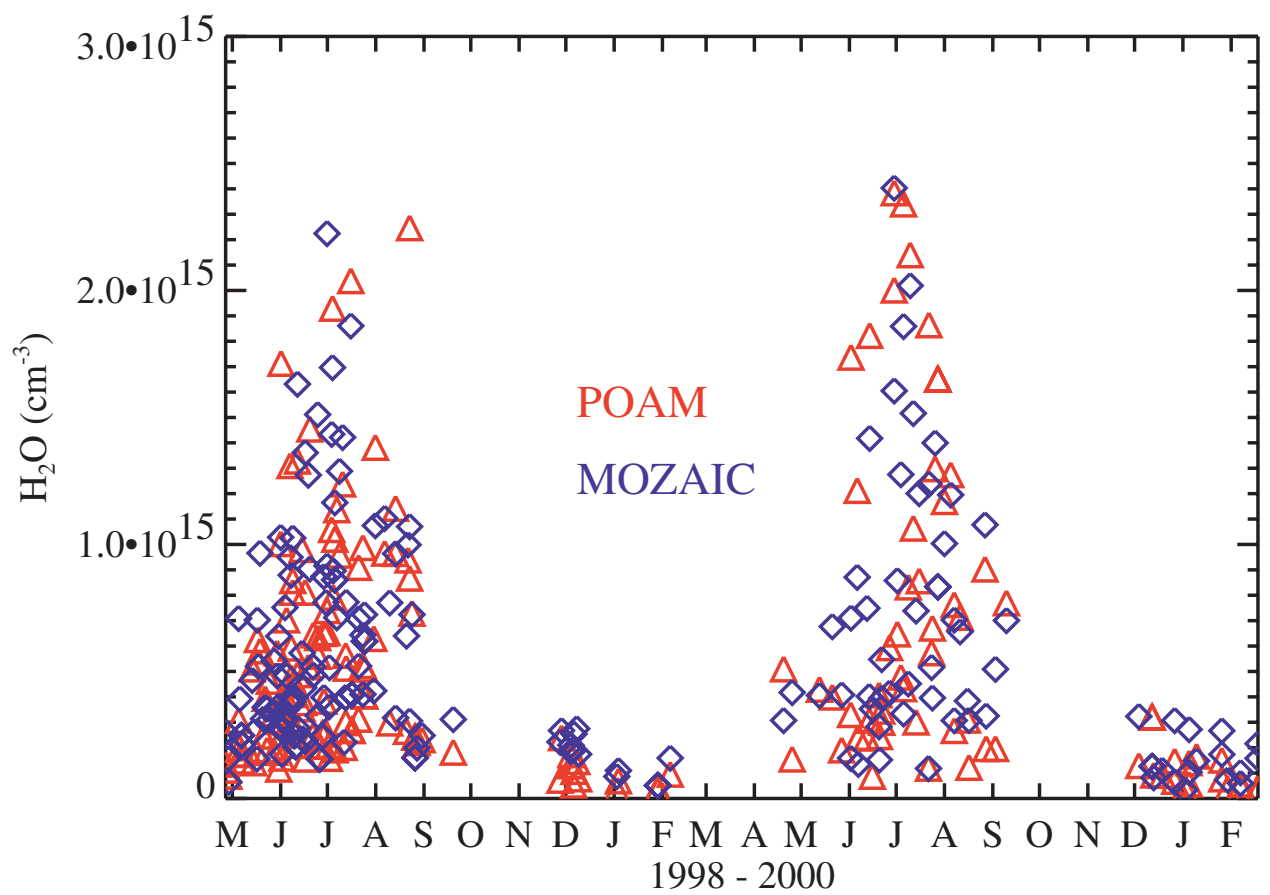

Figure 6. Water vapor concentrations from the coincident POAM (triangles) and MOZAIC (diamonds) measurements indicated in Figure 5.

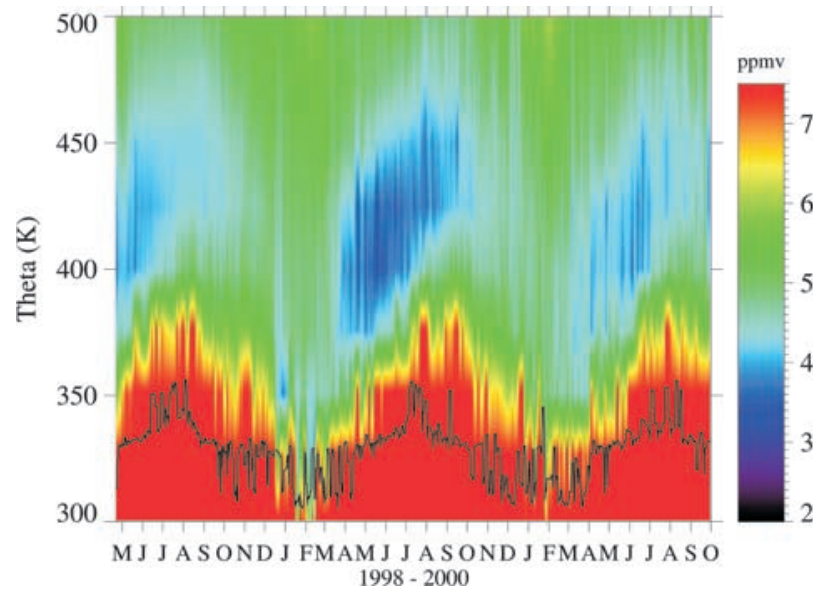

Figure 9. POAM Northern Hemisphere $\left(55^{\circ}-71^{\circ}\right)$ water vapor measurements as a function of potential temperature. The data are averaged as in Figure 8. 


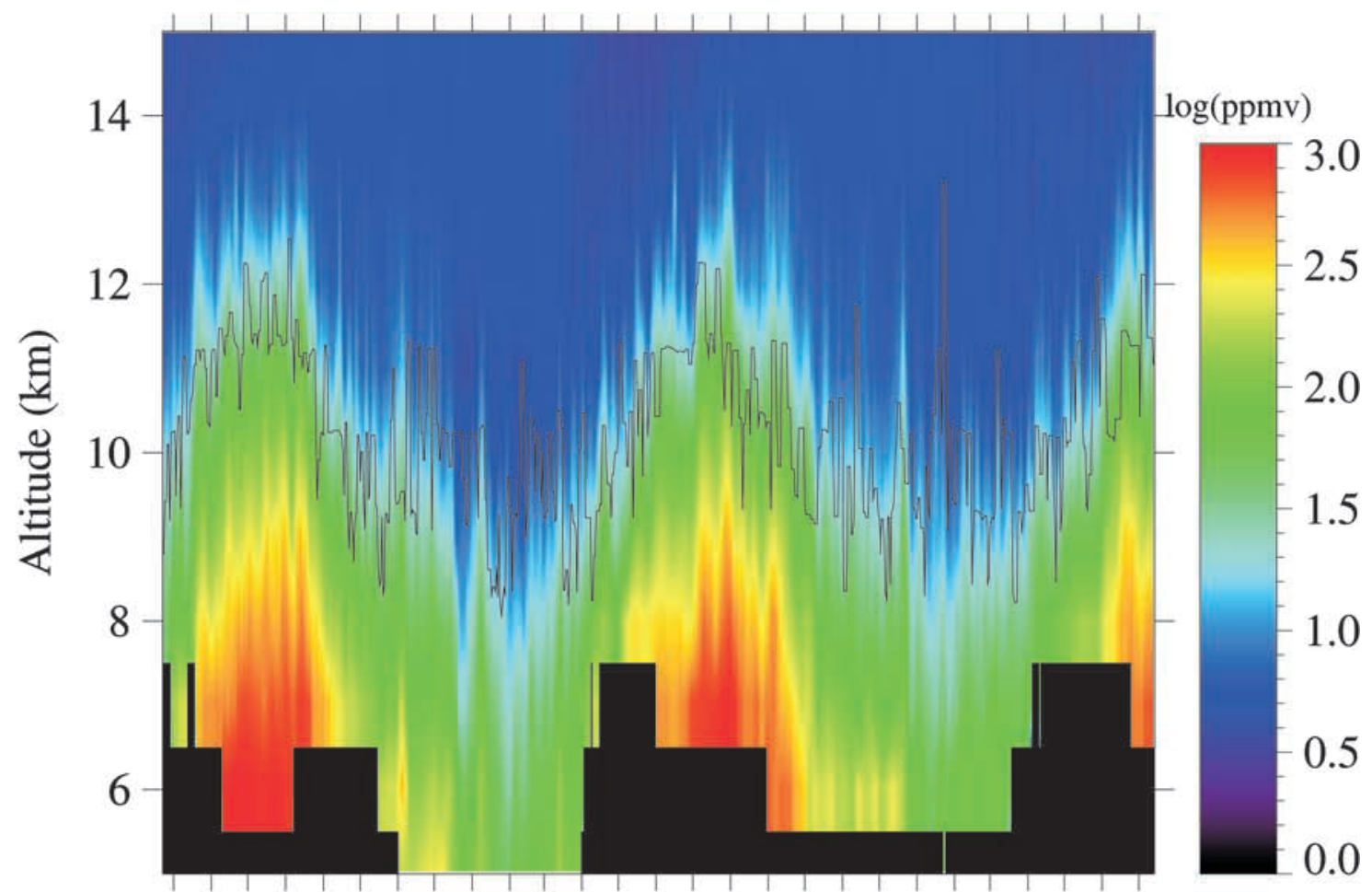

M J J A S OND J FMAM J J A S OND J FMAM J J $1998-2000$

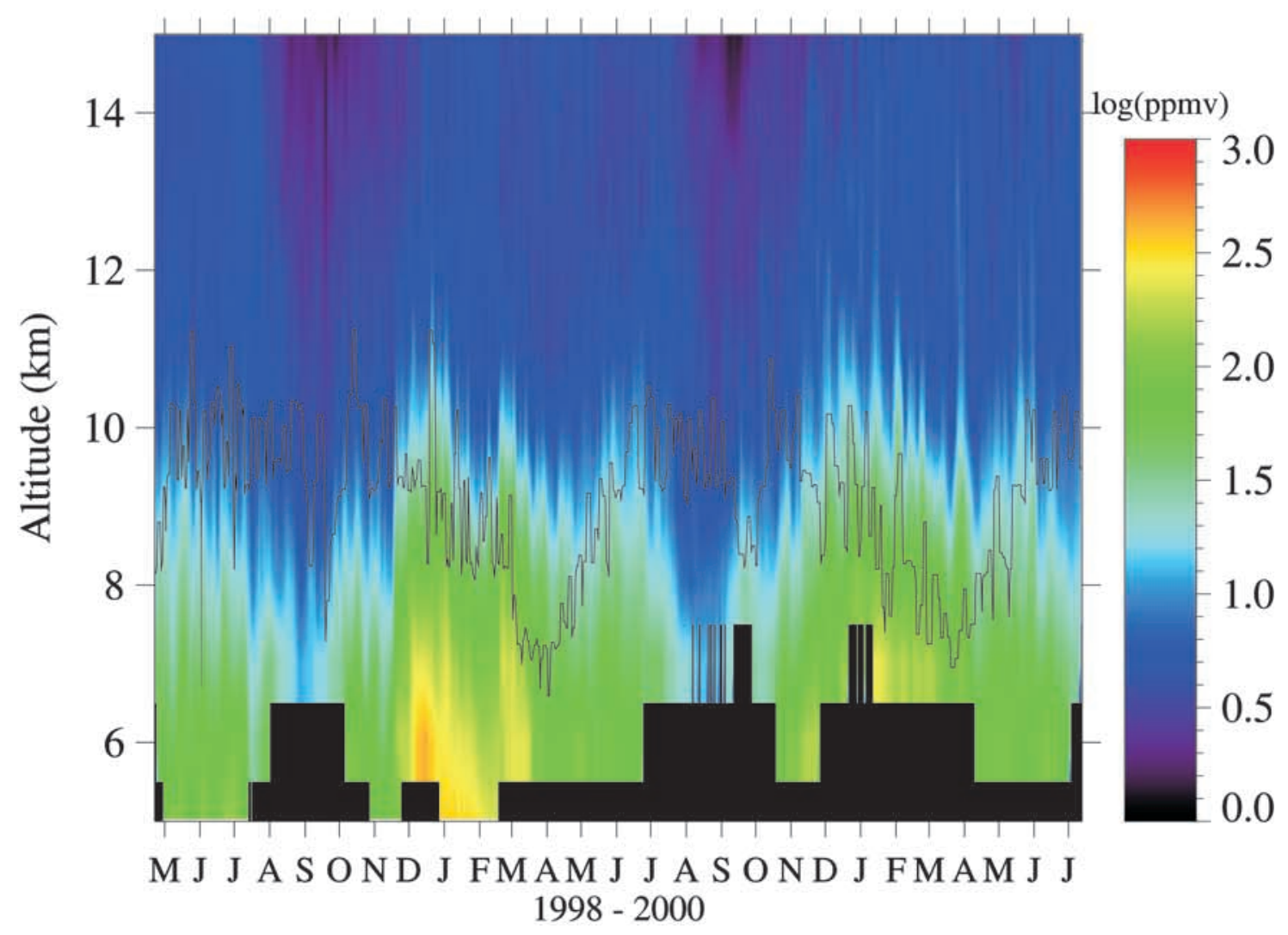

Figure 8. Water vapor mixing ratio measured by POAM at $55^{\circ} \mathrm{N}$ to $71^{\circ} \mathrm{N}$ in the troposphere and lowermost stratosphere. Note the logarithmic scale. The data are averaged as in Figure 3. Altitudes where $<14$ measurements are available over a 29 day period have been blacked out. Also indicated is the maximum 2 PVU tropopause height for the averaging period. 